\title{
Preparation of Dual Z-Scheme
}

Bi2Mo06/ZnSn03/ZnO Heterostructure

Photocatalyst for Efficient Visible Light Degradation of Organic Pollutants

\section{Yuanyingxue Gao}

Qiqihar University

Li Li ( $\sim$ qqhrlili@126.com )

Qiqihar University https://orcid.org/0000-0003-4577-7174

\section{Wenlin Zu}

Qiqihar University

\section{Yingru Sun}

Qiqihar University

Jiahui Guan

Qiqihar University

Yanzhen Cao

Qiqihar University

Haixia Yu

Qiqihar University

Wenzhi Zhang

Qiqihar University

\section{Research Article}

Keywords: Hydrothermal method, Heterojunction, Dual Z-scheme, Bi2Mo06/ZnSnO3/ZnO,

Photocatalysis, Crystal violet, Degradation mechanism

Posted Date: November 19th, 2021

DOI: https://doi.org/10.21203/rs.3.rs-1088317/v1

License: (9) (1) This work is licensed under a Creative Commons Attribution 4.0 International License.

Read Full License 
Version of Record: A version of this preprint was published at Journal of Inorganic and Organometallic Polymers and Materials on February 10th, 2022. See the published version at https://doi.org/10.1007/s10904-022-02242-y. 


\title{
Preparation of dual $\mathrm{Z}$-scheme $\mathrm{Bi}_{2} \mathrm{MoO}_{6} / \mathrm{ZnSnO}_{3} / \mathrm{ZnO}$ heterostructure photocatalyst for efficient visible light degradation of organic pollutants
}

\author{
Yuanyingxue $\mathrm{Gao}^{\mathrm{a}} \quad \mathrm{Li} \mathrm{Li}^{\mathrm{a}, \mathrm{b} *} \quad{\text { Wenlin } \mathrm{Zu}^{\mathrm{a}} \quad \text { Yingru Sun }^{\mathrm{a}} \quad \text { Jiahui Guan }}^{\mathrm{b}}$

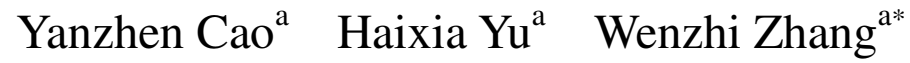 \\ ${ }^{a}$ College of Chemistry and Chemical Engineering, Qiqihar University, Qiqihar 161006, PR China \\ ${ }^{\mathrm{b}}$ College of Materials Science and Engineering, Qiqihar University, Qiqihar 161006, PR China
}

\begin{abstract}
An important means of achieving efficient charge separation and improving photocatalytic activity is the construction of heterostructures. In this study, the $\mathrm{Bi}_{2} \mathrm{MoO}_{6} / \mathrm{ZnSnO}_{3} / \mathrm{ZnO}$ heterostructure photocatalyst was synthesized by the hydrothermal method. The synthesized samples were carefully examined by X-ray photoelectron spectroscopy (XPS), $\mathrm{X}$-ray diffraction (XRD), scanning electron microscope (SEM), high-resolution transmission electron microscopy (HR-TEM), photoluminescence (PL), and other analytical techniques. Meanwhile, the photocatalytic performance was further evaluated by multi-mode photocatalytic degradation with crystal violet (CV). The results show that the composite material has a relatively homogeneous cubic structure in size and shape. In the cubic structure, a heterogeneous structure exists between $\mathrm{Bi}_{2} \mathrm{MoO}_{6}, \mathrm{ZnSnO}_{3}$ and $\mathrm{ZnO}$. Simultaneously, the dramatic changes in physical morphology, such as the specific surface area and particle size of the composites, led to a unique set of properties, such as a significant climb in light absorption properties and superior photocatalytic activity. In addition, the $\mathrm{Bi}_{2} \mathrm{MoO}_{6} / \mathrm{ZnSnO}_{3} / \mathrm{ZnO}$ composite material shows lower photoluminescence intensity, smaller arc radius, and stronger photocurrent response compared to $\mathrm{ZnO}, \mathrm{Bi}_{2} \mathrm{MoO}_{6}$ and $\mathrm{ZnSnO}_{3} / \mathrm{ZnO}$. Meanwhile, $\mathrm{Bi}_{2} \mathrm{MoO}_{6} / \mathrm{ZnSnO}_{3} / \mathrm{ZnO}$ shows higher photocatalytic efficiency for crystal violet (CV) and tetracycline hydrochloride (TC) and maintains good stability after 3 cycles of photodegradation experiments. Based on experimental results, the existence of heterojunctions between $\mathrm{ZnO}, \mathrm{ZnSnO}_{3}$ and $\mathrm{Bi}_{2} \mathrm{MoO}_{6}$ and the possible photocatalytic mechanism for
\end{abstract}

\footnotetext{
* Corresponding author: Li Li, Female, Ph.D., Professor, Doctoral tutor, mainly engaged in the preparation and photocatalytic properties of nanocomposites, +86 0452-2738867. E-mail: qqhrll@163.com; qqhrlili@126.com (L. Li).
} 
the degradation of crystal violet by dual Z-scheme composites are proposed. In conclusion, this study provides a feasible strategy for the photocatalytic degradation of organic pollutants by introducing $\mathrm{ZnSnO}_{3}$ and $\mathrm{Bi}_{2} \mathrm{MoO}_{6}$ to successfully construct composite catalysts with dual $\mathrm{Z}$-scheme heterostructures.

Keywords: Hydrothermal method; Heterojunction; Dual Z-scheme; $\mathrm{Bi}_{2} \mathrm{MoO}_{6} / \mathrm{ZnSnO}_{3} / \mathrm{ZnO}$; Photocatalysis; Crystal violet; Degradation mechanism

\section{Introduction}

In the last decades, rapid industrial development, population explosion, and the misuse of chemical disposal methods have resulted in environmental pollution and caused serious health problems to humans $[1,2]$. Among different wastewaters, the wastewater from the dye industry is one of the main causes of environmental pollution, especially water pollution [3-5]. Approximately 650,000 tons of different dyes are used in the production of textiles every year [6,7]. Various dyes are widely used in silk, wool, cotton dyeing, and other textile industries [8, 9]. Since these dyes do not have biodegradable and carcinogenic properties, they must be pretreated before emission [10].

Semiconductor photocatalysts have attracted extensive attention due to their wide application scopes in the direct elimination of harmful environmental pollutants, such as chromium, dyes, drugs, and other heavy metals using solar energy $[11,12]$. Among the various photocatalysts currently studied, zinc oxide $(\mathrm{ZnO})$ has been widely recognized as a photocatalytic material with great promise due to its unique physicochemical properties, photochemical stability, and nontoxicity [13, 14]. There are two main reasons for the low photocatalytic activity of pure zinc oxide. First, $\mathrm{ZnO}$ has a wide band gap value and therefore can only absorb ultraviolet (UV) light in the solar spectrum, which severely limits its photocatalytic applications [15]. Second, the rapid light-induced recombination rate of electron-hole pairs in $\mathrm{ZnO}$ severely reduces its photocatalytic efficiency [16]. Therefore, an effective strategy needs to be developed to extend the photoresponse range of $\mathrm{ZnO}$ in the UV region to the visible light part and keep it photoactive for a longer time.

Constructing semiconductor heterostructures by utilizing visible light active materials is a simple and effective way to enhance the photocatalytic performance of $\mathrm{ZnO}$ [17]. The reason for using this way is that the heterojunction interface in this heterostructure not only helps to expand its light absorption range, allowing it to absorb visible light, but also extends the carrier lifetime 
simultaneously [18]. Certain perovskite-type ternary compounds $\left(\mathrm{ABO}_{3}\right)$, such as $\mathrm{ZnTiO}_{3}$ and $\mathrm{ZnSnO}_{3}$, exhibit efficient photocatalytic degradation of organic pollutants at room temperature. In particular, $\mathrm{ZnSnO}_{3}$, as a famous functional material, shows promising applications in photoelectrochemical devices [19], photocatalysts [20], and gas sensors [21]. Bi(III)-containing oxides have attracted much attention in the field of photocatalysis due to their better intrinsic properties and special layered structures $[22,23]$. Remarkably, bismuth molybdate $\left(\mathrm{Bi}_{2} \mathrm{MoO}_{6}\right)$ is composed of alternating perovskite $\left[\mathrm{Bi}_{2} \mathrm{O}_{2}\right]^{2+}$ and $\left(\mathrm{MoO}_{4}{ }^{2-}\right)$ layers, which gives it a manageable morphology and a suitable band gap value $(2.5-2.7 \mathrm{eV})$ to capture visible light $[24,25]$. Since the band gap value of $\mathrm{Bi}_{2} \mathrm{MoO}_{6}$ matches that of $\mathrm{ZnO}$, it can inhibit the binding of electron-hole pairs, and is a promising catalyst. So far, there are relatively few reports on $\mathrm{ZnSnO}_{3} / \mathrm{ZnO}$ composites. Although the $\mathrm{ZnSnO}_{3} / \mathrm{ZnO}$ composites have been successfully prepared, most of them are of irregular stacking morphology synthesized in two steps [26]. Van-Huy Nguyen et al. [27] prepared a new type of $\mathrm{ZnO} / \mathrm{ZnSnO}_{3} /$ carbon dots hybrid nanocomposite by hydrothermal method. The photocatalytic immobilization of $\mathrm{N}_{2}$ by the $\mathrm{ZnO} / \mathrm{ZnSnO}_{3} /$ carbon dots ternary system was studied. It was concluded that the system $(0.5 \mathrm{~mL})$ of $\mathrm{ZnO} / \mathrm{ZnSnO}_{3} /$ Carbon dots showed significant activity during photocatalytic immobilization of $\mathrm{N}_{2}$. Related studies have revealed that $\mathrm{ZnO} \mathrm{NW} / \mathrm{ZnSnO}_{3}$ $\mathrm{NC}_{\mathrm{S}}$ heterostructures are emerging as one of the semiconductor nanocomposites with remarkable stability and high durability [28].

In this study, the composite $\mathrm{Bi}_{2} \mathrm{MoO}_{6} / \mathrm{ZnSnO}_{3} / \mathrm{ZnO}$ was synthesized by the hydrothermal method. The main ideas of this study are described as follows. First, the hydrothermal method was used for affecting the photocatalytic performance as well as the physical properties of the synthesized samples. Then, the photocatalytic activity of $\mathrm{ZnO}$ was enhanced by the introduction of $\mathrm{ZnSnO}_{3}$. The $\mathrm{ZnSnO}_{3} / \mathrm{ZnO}$ composite had only UV light absorption ability, while the introduction of $\mathrm{Bi}_{2} \mathrm{MoO}_{6}$ in this composite extended the response spectrum of the composite into the visible region and improved the light absorption ability of the composite photocatalyst. Moreover, the mixture of $\mathrm{Bi}_{2} \mathrm{MoO}_{6}$ and $\mathrm{ZnSnO}_{3} / \mathrm{ZnO}$ can establish a heterostructure between $\mathrm{Bi}_{2} \mathrm{MoO}_{6}, \mathrm{ZnSnO}_{3}$, and $\mathrm{ZnO}$ in the composites to achieve efficient multichannel electron transfer for the successful separation of photogenerated carriers. Therefore, it is expected that the construction of heterostructures between $\mathrm{Bi}_{2} \mathrm{MoO}_{6}, \mathrm{ZnSnO}_{3}$, and $\mathrm{ZnO}$ can further improve their photocatalytic activities. 


\section{Experimental part}

See the supplementary material for a detailed experimental procedure.

\section{Results and discussion}

\subsection{XRD analysis}

The crystal structures of the synthesized composites were analyzed using X-ray diffraction (XRD). As shown in Fig $1, \mathrm{ZnO}$ has diffraction peaks at $31.8^{\circ}, 36.2^{\circ}, 47.5^{\circ}, 56.6^{\circ}$, and $68.2^{\circ}$, corresponding to the (100), (102), (110), (103), and (112) crystal planes, respectively, indicating that the $\mathrm{ZnO}$ in the composites belongs to the hexagonal wurtzite structure (JCPDS\#36-1451). The diffraction peaks of this sample are sharp, indicating that the as-synthesized $\mathrm{ZnO}$ has excellent crystallinity. The diffraction peaks of the composites at $28.3^{\circ}$ and $55.4^{\circ}$ correspond to the (131) and (331) crystal planes of $\mathrm{Bi}_{2} \mathrm{MoO}_{6}$, respectively (JCPDS\#21-0102). The diffraction peaks of the composites are at $23.1^{\circ}, 33.9^{\circ}, 59.5^{\circ}$, and $89.7^{\circ}$, corresponding to the (012), (110), (214), and (309) crystal planes of $\mathrm{ZnSnO}_{3}$ (JCPDS\#52-1381), respectively. Moreover, these diffraction peaks of this composite are sharp without redundant hetero peaks, indicating that the crystallinity of the as-synthesized sample is excellent, and no impurities were introduced. Compared with the $\mathrm{ZnSnO}_{3} / \mathrm{ZnO}$ composite, the intensity and type of the diffraction peak of $\mathrm{Bi}_{2} \mathrm{MoO}_{6} / \mathrm{ZnSnO}_{3} / \mathrm{ZnO}$ composite are slightly weakened due to the reduced crystallinity of the composite after secondary hydrothermal. In addition, the diffraction peaks of the $\mathrm{Bi}_{2} \mathrm{MoO}_{6} / \mathrm{ZnSnO}_{3} / \mathrm{ZnO}$ composite are slightly wider than those of the other materials, suggesting that the as-synthesized composite has smaller grain sizes, which may be the result of the secondary hydrothermal.

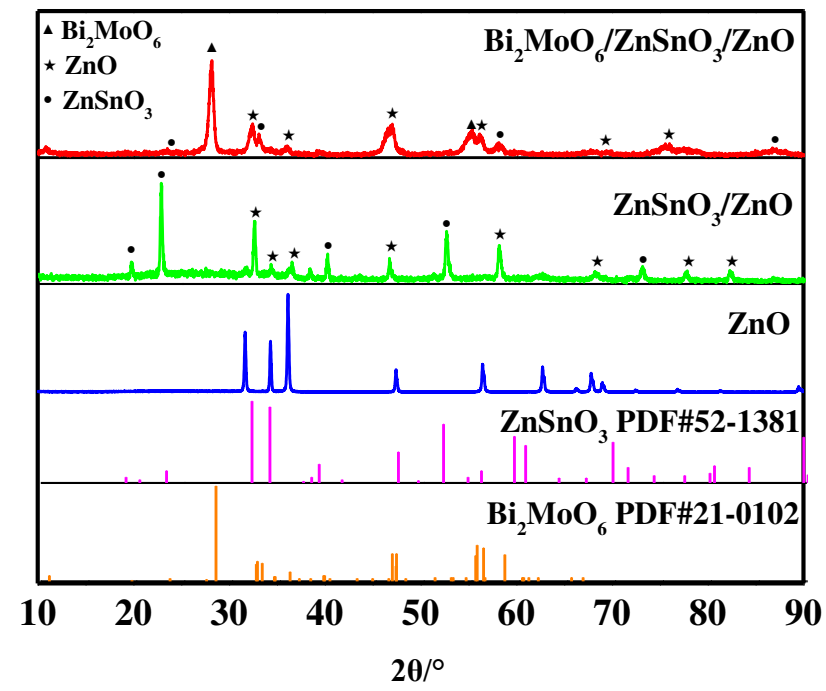


Fig 1 XRD spectra of $\mathrm{ZnO}, \mathrm{ZnSnO}_{3} / \mathrm{ZnO}$ and $\mathrm{Bi}_{2} \mathrm{MoO}_{6} / \mathrm{ZnSnO}{ }_{3} / \mathrm{ZnO}$.

The average crystallite size of each material was calculated by Scherrer's equation (Eq 1), and the results are shown in Table1.

$$
d=K \lambda /(\beta \cos \theta)
$$

In the equation, $d$ is the average grain diameter of the grains, $K$ is constant $0.89, \beta$ is the half-height width of the diffraction peak of the sample, $\lambda$ is X-ray wavelength of $1.54056 \mathrm{~nm}, \theta$ is the Bragg angle corresponding to the diffraction peak. As shown in Table 1, crystallite sizes of pure $\mathrm{ZnO}, \mathrm{ZnSnO}_{3} / \mathrm{ZnO}$, and $\mathrm{Bi}_{2} \mathrm{MoO}_{6} / \mathrm{ZnSnO}_{3} / \mathrm{ZnO}$ are $40.03 \mathrm{~nm}, 35.35 \mathrm{~nm}$, and $10.65 \mathrm{~nm}$, respectively, showing a decreasing trend. Due to the stronger binding force of $\mathrm{ZnSnO}_{3}$ and $\mathrm{ZnO}$, the crystallite size of $\mathrm{ZnSnO}_{3} / \mathrm{ZnO}$ and $\mathrm{Bi}_{2} \mathrm{MoO}_{6} / \mathrm{ZnSnO}_{3} / \mathrm{ZnO}$ composites decreased compared to that of pure $\mathrm{ZnO}$. Furthermore, the composites are not destroyed by secondary hydrothermal effect after the $\mathrm{Bi}_{2} \mathrm{MoO}_{6}$ loading. Meanwhile, the crystallite size of the composites becomes small because the temperature programming device is characterized by fast and uniform heating, and the uniform temperature distribution within the crystal ensures uniform crystallite distribution.

Table 1 Crystallite sizes (d) and band gap energy values (Eg) of $\mathrm{ZnO}, \mathrm{ZnSnO}_{3} / \mathrm{ZnO}$ and $\mathrm{Bi}_{2} \mathrm{MoO}_{6} / \mathrm{ZnSnO}{ }_{3} / \mathrm{ZnO}$.

\begin{tabular}{|c|c|c|}
\hline Sample & $\mathrm{d} / \mathrm{nm}$ & $\mathrm{Eg} / \mathrm{eV}$ \\
\hline $\mathrm{ZnO}$ & 40.03 & 3.24 \\
\hline $\mathrm{ZnSnO}_{3} / \mathrm{ZnO}$ & 35.35 & 3.02 \\
\hline $\mathrm{Bi}_{2} \mathrm{MoO}_{6} / \mathrm{ZnSnO}{ }_{3} / \mathrm{ZnO}$ & 10.65 & 2.83 \\
\hline
\end{tabular}

\subsection{SEM-EDS}

To investigate the morphological features and elemental distribution of the composites, SEM analysis and EDS analysis were performed on $\mathrm{Bi}_{2} \mathrm{MoO}_{6} / \mathrm{ZnSnO}_{3} / \mathrm{ZnO}$ composite. Fig 2 (a-d) are SEM images of different materials, where the monomeric $\mathrm{ZnO}$ exhibits a rod-like structure with a diameter of about $400 \mathrm{~nm}$ (Fig 2a). The $\mathrm{ZnSnO}_{3} / \mathrm{ZnO}$ material synthesized by the hydrothermal method exhibits a cubic structure with heterogeneous particles attached to the surface (Fig 2b). After secondary hydrothermal treatment, the morphology of $\mathrm{Bi}_{2} \mathrm{MoO}_{6} / \mathrm{ZnSnO}_{3} / \mathrm{ZnO}$ composite in Fig 2 (c) does not change much compared with $\mathrm{ZnSnO}_{3} / \mathrm{ZnO}$, indicating that secondary hydrothermal did not affect the morphology of the composite. It can be found from the figure that the morphological size of the composites is around $1 \mu \mathrm{m}$. Fig 2 (e-i) show the EDS elemental 
analysis of the composites in the range of Fig 2 (d), from which it can be found that all elements are evenly distributed. The analysis of the contents of each element in the composites is shown in Fig S1.

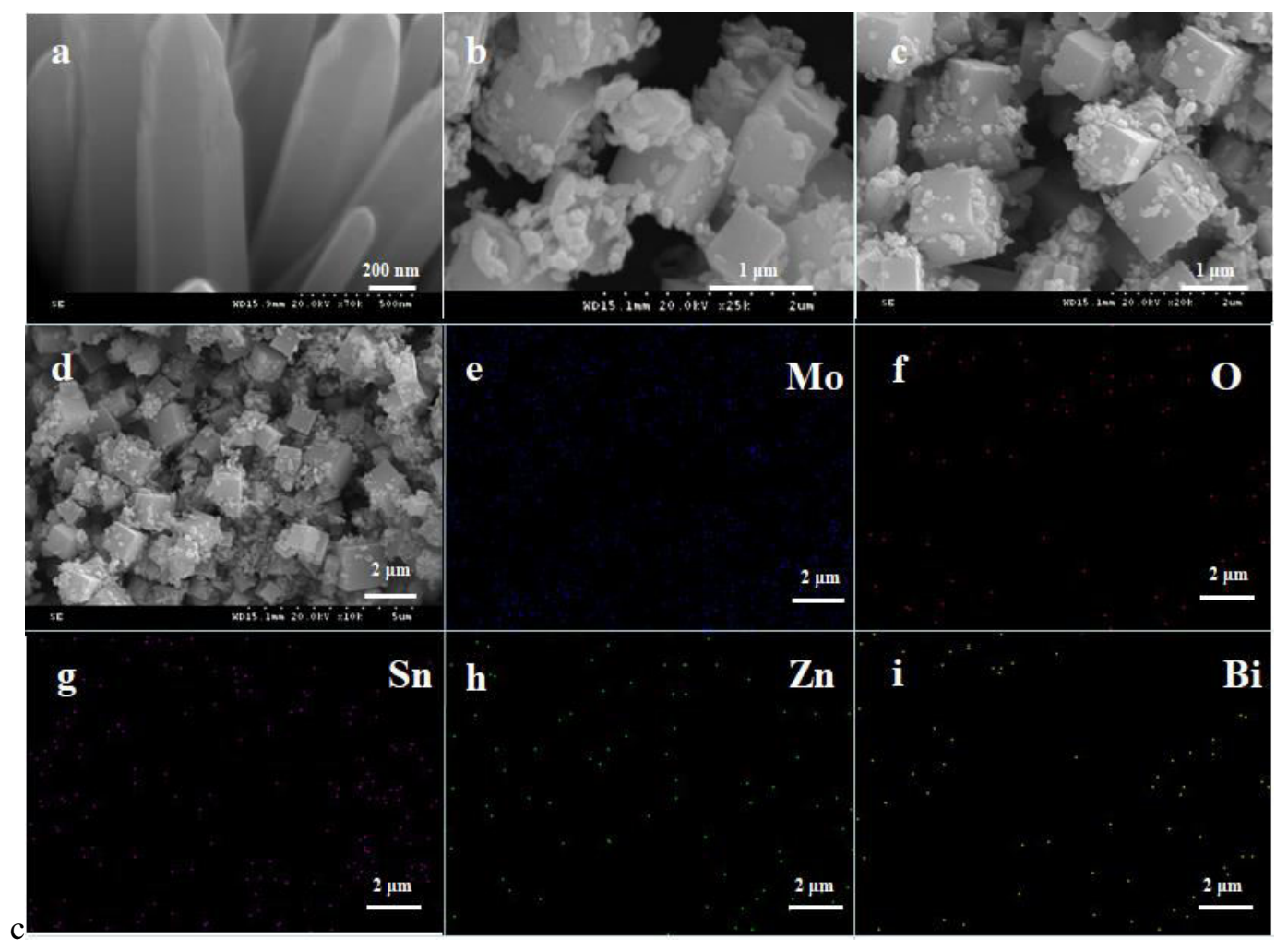

Fig 2 SEM images of $\mathrm{ZnO}(\mathrm{a}), \mathrm{ZnSnO}_{3} / \mathrm{ZnO}$ (b), $\mathrm{Bi}_{2} \mathrm{MoO}_{6} / \mathrm{ZnSnO}_{3} / \mathrm{ZnO}$ (c) and $\mathrm{EDS}$ images of $\mathrm{Bi}_{2} \mathrm{MoO}_{6} / \mathrm{ZnSnO}_{3} / \mathrm{ZnO}$ composite(d)-(i).

\subsection{TEM and HR-TEM}

To further investigate the morphology of the $\mathrm{Bi}_{2} \mathrm{MoO}_{6} / \mathrm{ZnSnO}_{3} / \mathrm{ZnO}$ composite, TEM and HR-TEM analyses were performed. TEM images of the composites are shown in Fig 3 (a), from which the composites exhibit a solid structure. Through the HR-TEM images (b-f) of the composite, it can be seen that the lattice spacing of $0.28 \mathrm{~nm}$ corresponds to the (100) crystal plane of $\mathrm{ZnO}$ [29], the lattice spacing of $0.31 \mathrm{~nm}$ corresponds to the (131) crystal plane of $\mathrm{Bi}_{2} \mathrm{MoO}_{6}$ [30], and the lattice spacing of $0.23 \mathrm{~nm}$ corresponds to the (200) crystal plane of $\mathrm{ZnSnO}_{3}$ [31]. The above results indicate that in the as-synthesized $\mathrm{Bi}_{2} \mathrm{MoO}_{6} / \mathrm{ZnSnO}_{3} / \mathrm{ZnO}$ composites, tight junctions were formed between $\mathrm{ZnSnO}_{3}$ and $\mathrm{ZnO}$, thus forming heterojunctions, which are beneficial to enhance the separation rate of photogenerated carriers and thus enhance the separation efficiency of photogenerated electron hole pairs. Moreover, because the $\mathrm{Bi}_{2} \mathrm{MoO}_{6}$ has a more negative conduction band potential than $\mathrm{ZnO}$, it can significantly inhibit the rapid recombination of 
photogenerated carriers inside $\mathrm{ZnO}$, and improve the lifetime of photogenerated carriers in the composites.

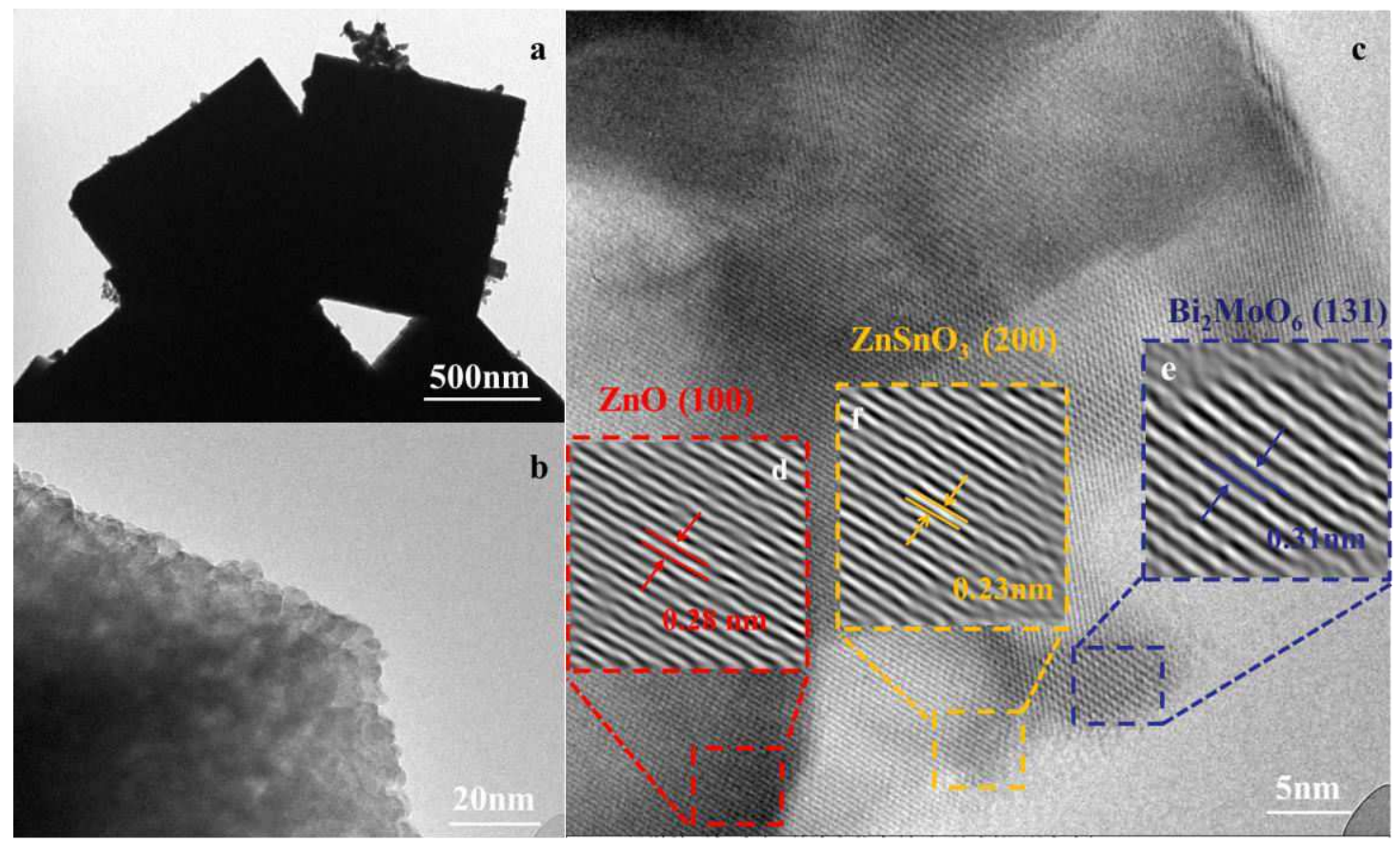

Fig 3 TEM image (a), and HR-TEM images of the $\mathrm{Bi}_{2} \mathrm{MoO}_{6} / \mathrm{ZnSnO}_{3} / \mathrm{ZnO}$ composite (b)-(c).

\subsection{XPS analysis}

XPS was used to analyze the chemical form of the surface element of the composite $\mathrm{Bi}_{2} \mathrm{MoO}_{6} / \mathrm{ZnSnO}_{3} / \mathrm{ZnO}$. Fig 4 (a) shows that the peaks correspond to five elements, including $\mathrm{Zn}, \mathrm{Bi}$, O, Mo, and Sn. Two characteristic peaks at 1043.72 and $1020.37 \mathrm{eV}$ of electron binding energy in Fig 4 (b) correspond to $\mathrm{Zn} 2 \mathrm{p}_{3 / 2}$ and $\mathrm{Zn} 2 \mathrm{p}_{1 / 2}$, proving that the $\mathrm{Zn}$ element exists $\mathrm{Zn}^{2+}$ form [13]. Figure 4 (c) shows that two strong peaks at 158.16 and $163.46 \mathrm{eV}$ appear in the $\mathrm{Bi} 4 \mathrm{f}$ region, illustrating that $\mathrm{Bi}$ exists in the $\mathrm{Bi}^{3+}$ form $[32,33]$. Fig 4 (d) shows the XPS spectrum of $\mathrm{O}$ at $\mathrm{O} 1 \mathrm{~s}$ in the composite $\mathrm{Bi}_{2} \mathrm{MoO}_{6} / \mathrm{ZnSnO}_{3} / \mathrm{ZnO}$ with electron binding energy region at $528.8 \mathrm{eV}, 529.79 \mathrm{eV}$, and $531.03 \mathrm{eV}$, corresponding to the characteristic peaks of lattice oxygen $(\mathrm{Zn}-\mathrm{O})$ and adsorbed oxygen [34]. The peaks at binding energies of $231.01 \mathrm{eV}$ and $234.47 \mathrm{eV}$ (Fig 4 e) correspond to Mo $3 \mathrm{~d}_{5 / 2}$ and $\mathrm{Mo} 3 \mathrm{~d}_{3 / 2}$ of $\mathrm{Mo}^{6+}$ in $\mathrm{Bi}_{2} \mathrm{MoO}_{6}$, respectively [35]. In Fig. 4 (e), the peak at the binding energy of $232.2 \mathrm{eV}$ may result from the oxygen vacancy generation in the composites, and the electronic reconstruction between chemical bonds changes the valence state of Mo [35]. The binding energy peaks at 485.43 and $494.29 \mathrm{eV}$ in Fig 4 (f) correspond to $\mathrm{Sn} 3 \mathrm{~d}_{3 / 2}$ and $\mathrm{Sn} 3 \mathrm{~d}_{5 / 2}$ of 
$\mathrm{Sn}^{4+}$, respectively [36]. The above results can further demonstrate the existence of each species in the composite $\mathrm{Bi}_{2} \mathrm{MoO}_{6} / \mathrm{ZnSnO}_{3} / \mathrm{ZnO}$.
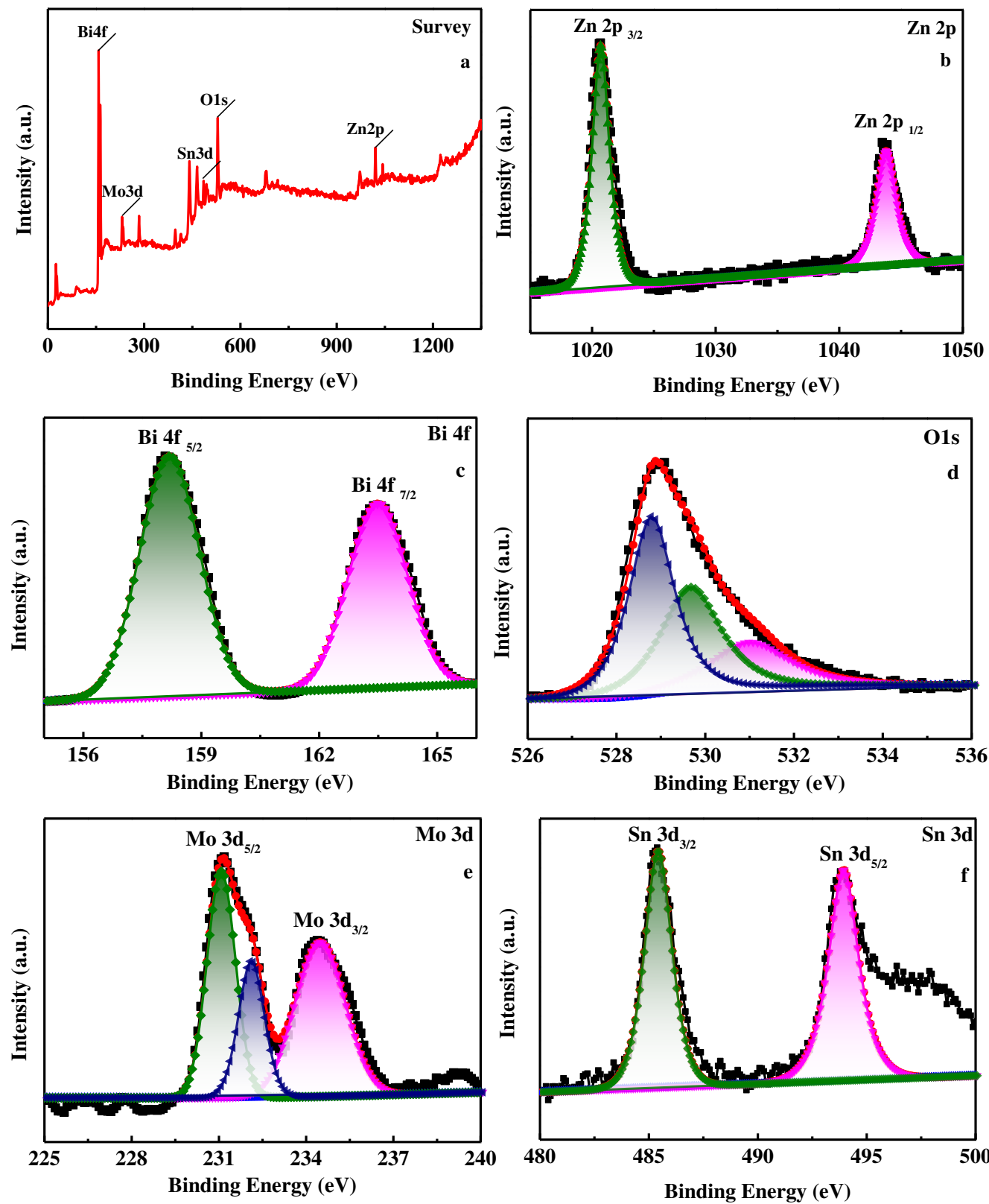

Fig 4 XPS spectra of $\mathrm{Bi}_{2} \mathrm{MoO}_{6} / \mathrm{ZnSnO}_{3} / \mathrm{ZnO}$ composite: (a) XPS full spectrum, (b) $\mathrm{Zn} 2 \mathrm{p}$, (c) Bi 4f, (d) O 1s, (e) Mo 3d, (f) Sn 3d.

\section{$3.5 \mathrm{~N}_{2}$ adsorption-desorption analysis}

The surface area can usually impact the adsorption and catalytic performance of photocatalysts. In order to investigate the surface physicochemical characteristics of the $\mathrm{Bi}_{2} \mathrm{MoO}_{6} / \mathrm{ZnSnO}_{3} / \mathrm{ZnO}$ composite, nitrogen adsorption-desorption isotherms were used to characterize $\mathrm{ZnO}, \mathrm{ZnSnO}_{3} / \mathrm{ZnO}$, and $\mathrm{Bi}_{2} \mathrm{MoO}_{6} / \mathrm{ZnSnO}_{3} / \mathrm{ZnO}$ composite. Fig S2 and Table S1 show that the $\mathrm{Bi}_{2} \mathrm{MoO}_{6} / \mathrm{ZnSnO}_{3} / \mathrm{ZnO}$ composite exhibits a larger specific surface area than pure $\mathrm{ZnO}$. The IUPAC definition shows that 
isotherms of each sample in Fig S2 are of type IV, indicating that the different samples prepared all have a mesoporous structure. The above materials have the same type of hysteresis loop as the H3 type hysteresis loop. The formation of this hysteresis loop is mainly due to the capillary condensation phenomenon in mesopores. The inset of Fig S2 shows the pore size distribution curve of each material. The pore size distribution of $\mathrm{ZnO}$ and $\mathrm{ZnSnO}_{3} / \mathrm{ZnO}$ is relatively concentrated, while that of $\mathrm{Bi}_{2} \mathrm{MoO}_{6} / \mathrm{ZnSnO}_{3} / \mathrm{ZnO}$ composites is relatively broad. Table $\mathrm{S} 1$ shows that the average pore size, specific surface area, and pore volume of $\mathrm{Bi}_{2} \mathrm{MoO}_{6} / \mathrm{ZnSnO}_{3} / \mathrm{ZnO}$ composites are larger than those of monomeric $\mathrm{ZnO}$ and $\mathrm{ZnSnO}_{3} / \mathrm{ZnO}$, and the pore size distribution is better than that of monomeric $\mathrm{ZnO}$ and $\mathrm{ZnSnO}_{3} / \mathrm{ZnO}$, indicating that the composite after loading $\mathrm{Bi}_{2} \mathrm{MoO}_{6}$ can both effectively improve the specific surface area of the catalysts and optimize the pore size distribution, thereby reducing the substance diffusion resistance. Therefore, it is beneficial to improve the photocatalytic activity of the composite.

\subsection{UV-vis/DRS analysis}

In order to determine whether the samples have the absorption in the ultraviolet and visible regions, the results of the UV-visible diffuse reflectance were exhibited in Fig 5. The absorption spectra of different catalysts are shown in Fig 5 (a). The Kubelka-Munk energy plots for different samples are shown in Fig 5 (b). Fig 5 (a) shows that the absorption edge of $\mathrm{ZnO}$ is around $400 \mathrm{~nm}$ due to its wide band gap value. In contrast, pure $\mathrm{Bi}_{2} \mathrm{MoO}_{6}$ has an absorption edge at approximately $500 \mathrm{~nm}$, consistent with previous reports showing light absorption in UV light and visible light regions. Besides, the visible light absorption ability of $\mathrm{ZnSnO}_{3} / \mathrm{ZnO}$ composites is improved compared with $\mathrm{ZnO}$. Since $\mathrm{Bi}_{2} \mathrm{MoO}_{6}$ has visible light absorption, the light absorption band edge of the composites is red-shifted with about $90 \mathrm{~nm}$ after loading of $\mathrm{Bi}_{2} \mathrm{MoO}_{6}$.
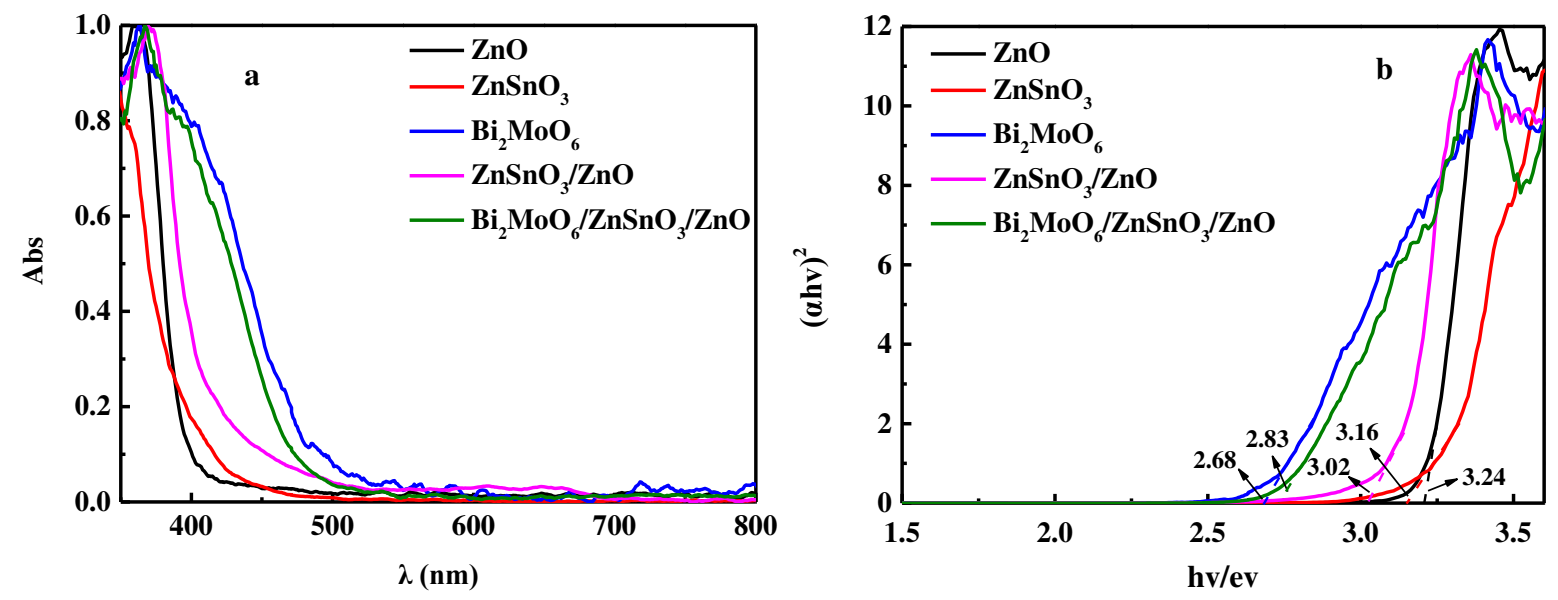
Fig 5 The (a) UV-vis/DRS absorption spectra and (b) Kubelka-Munk energy curve plots for different samples

Eq 2 is used to determine the nature of transition and obtain the band gap of the sample.

$$
\alpha h v=A \cdot(h v-E g)^{n / 2}
$$

where $\alpha, h v$, and $A$ are the absorption coefficient, discrete photon energy, and constant. Besides, the value of $\mathrm{n}$ is determined by the type of optical transition in the semiconductor $(\mathrm{n}=1$ for direct transition and $\mathrm{n}=4$ for indirect transition). Since both $\mathrm{ZnO}$ and $\mathrm{Bi}_{2} \mathrm{MoO}_{6}$ belong to indirect transition semiconductors, their $\mathrm{n}$ values are both 4 . The $(\alpha h v)^{2}$ and $h v$ curves of $\mathrm{ZnO}$ and $\mathrm{Bi}_{2} \mathrm{MoO}_{6}$ are shown in Fig 5 (b). The band gap values of $\mathrm{ZnO}$ and $\mathrm{Bi}_{2} \mathrm{MoO}_{6}$ are about 3.24 and $2.68 \mathrm{eV}$, close to the values reported previously. The tangent treatment to the Kubelka-Munk energy curve shows that band gap values of $\mathrm{ZnSnO}_{3} / \mathrm{ZnO}$, and $\mathrm{Bi}_{2} \mathrm{MoO}_{6} / \mathrm{ZnSnO}_{3} / \mathrm{ZnO}$ composites are $3.02 \mathrm{eV}$ and 2.83 $\mathrm{eV}$, respectively. After the successful loading of $\mathrm{Bi}_{2} \mathrm{MoO}_{6}$, the band gap values of the composites are further reduced. The above results illustrate that $\mathrm{Bi}_{2} \mathrm{MoO}_{6}$ is successfully loaded on $\mathrm{ZnSnO}_{3} / \mathrm{ZnO}$, further reducing the band gap of the composites. Besides, $\mathrm{Bi}_{2} \mathrm{MoO}_{6}$ is expected to improve the photocatalytic activity of the composites.

\subsection{Photoelectrochemical performance}

The transfer and recombination of the photoinduced electron hole pairs in the photocatalytic materials were investigated by performing PL, EIS and transient photocurrent analysis of the composites. The photoluminescence test was performed by exciting the $\mathrm{Bi}_{2} \mathrm{MoO}_{6} / \mathrm{ZnSnO}_{3} / \mathrm{ZnO}$ composite with $500 \mathrm{~nm}$ light. A lower photoluminescence intensity implies a lower recombination rate of photoluminescent electron-hole pairs, thus leading to a higher photocatalytic activity of semiconductor composites. As shown in Fig 6, photoluminescence intensity is $\mathrm{ZnO}>\mathrm{ZnSnO}_{3} / \mathrm{ZnO}>$ $\mathrm{Bi}_{2} \mathrm{MoO}_{6} / \mathrm{ZnSnO}_{3} / \mathrm{ZnO}$, and $\mathrm{Bi}_{2} \mathrm{MoO}_{6} / \mathrm{ZnSnO}_{3} / \mathrm{ZnO}$ exhibits the lowest luminescence intensity, indicating that it has the lowest electron hole recombination rate. Besides, adding $\mathrm{ZnSnO}_{3}$ and $\mathrm{Bi}_{2} \mathrm{MoO}_{6}$ can effectively inhibit the fast combination of electron and hole pairs in the composites.

In order to study the separation and recombination efficiency of electron-hole pairs in different materials, electrochemical impedance spectroscopy (EIS) tests are performed, as shown in Fig 7 (a). The arc radius of $\mathrm{Bi}_{2} \mathrm{MoO}_{6} / \mathrm{ZnSnO}_{3} / \mathrm{ZnO}$ composite is smaller than that of $\mathrm{ZnSnO}_{3} / \mathrm{ZnO}$ and $\mathrm{ZnO}$, indicating that the interfacial charge transfer resistance is somewhat reduced and the recombination of electrons and holes in the composites is suppressed. Fig 7 (b) shows the transient photocurrent 
responses of $\mathrm{ZnO}, \mathrm{ZnSnO}_{3} / \mathrm{ZnO}$, and $\mathrm{Bi}_{2} \mathrm{MoO}_{6} / \mathrm{ZnSnO}_{3} / \mathrm{ZnO}$ composites during several cycles of switching on and off visible light illumination. The photocurrent intensity increases rapidly when the visible light is turned on and decreases directly when the visible light is turned off. Among other photocatalysts, $\mathrm{Bi}_{2} \mathrm{MoO}_{6} / \mathrm{ZnSnO}_{3} / \mathrm{ZnO}$ exhibits the strongest photocurrent response. The enhancement of photocurrent response corresponds to the enhancement of charge separation performance, thus leading to enhanced photocatalytic efficiency.
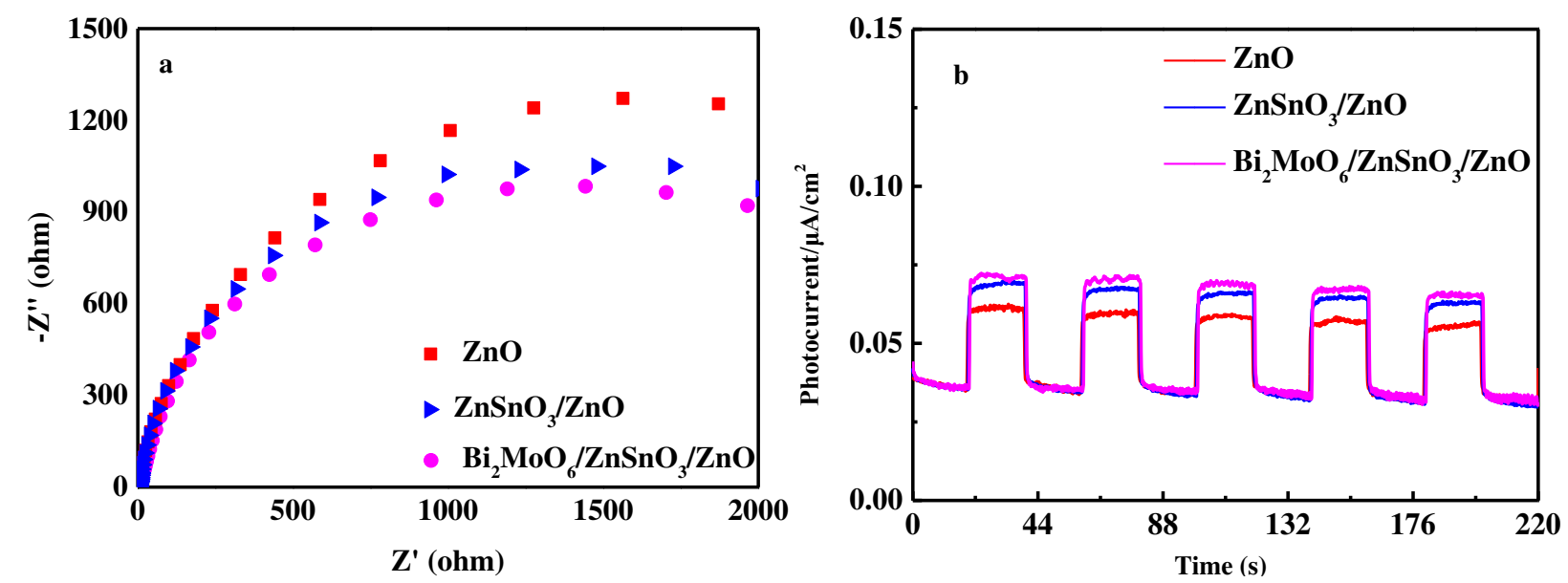

Fig 7 EIS Nyquist plots (a) and transient photocurrent response analysis (b) of different composites.

\subsection{Photocatalytic performance}

The photocatalytic performance of the composites was analyzed by performing multi-modal photocatalytic experiments under UV, visible and simulated solar light, as shown in Fig. 8. Within identical experimental conditions, the degradation efficiency of $\mathrm{Bi}_{2} \mathrm{MoO}_{6} / \mathrm{ZnSnO}_{3} / \mathrm{ZnO}$ composite to crystal violet under UV light irradiation can reach $90 \%$ within $120 \mathrm{~min}$. The composite shows the best degradation effect on crystal violet under UV light. Therefore, crystal violet is chosen as the model molecule in this paper. The composites degrade other dyes and tetracycline hydrochloride under UV light irradiation, as shown in Fig 8 (c), indicating that the composites can degrade different organic pollutants. In order to further investigate the effect of the $\mathrm{Bi}_{2} \mathrm{MoO}_{6} / \mathrm{ZnSnO}_{3} / \mathrm{ZnO}$ catalyst on the $\mathrm{CV}$ degradation, the photodegradation activity of pure $\mathrm{ZnO}, \mathrm{Bi}_{2} \mathrm{MoO}_{6}, \mathrm{ZnSnO}_{3} / \mathrm{ZnO}$, and $\mathrm{Bi}_{2} \mathrm{MoO}_{6} / \mathrm{ZnSnO}_{3} / \mathrm{ZnO}$ was examined under ultraviolet light irradiation. In Fig 8 (a), the photocatalytic activity of $\mathrm{Bi}_{2} \mathrm{MoO}_{6} / \mathrm{ZnSnO}_{3} / \mathrm{ZnO}$ under $\mathrm{UV}$ light irradiation is higher than that of the other samples, and the photocatalytic efficiency is 4.2 times that of monomeric $\mathrm{ZnO}$ and 0.7 times that of $\mathrm{ZnSnO}_{3} / \mathrm{ZnO}$, whose photocatalytic efficiency is significantly improved, consistent with the results of UV-vis diffuse reflectance absorption spectra. The UV-vis spectra of CV at 
different degradation times with $0.15 \mathrm{~g} \mathrm{Bi}_{2} \mathrm{MoO}_{6} / \mathrm{ZnSnO}_{3} / \mathrm{ZnO}\left(\mathrm{CV}\right.$ concentration of $\left.50 \mathrm{mg} \cdot \mathrm{L}^{-1}\right)$ is shown in Fig S3.
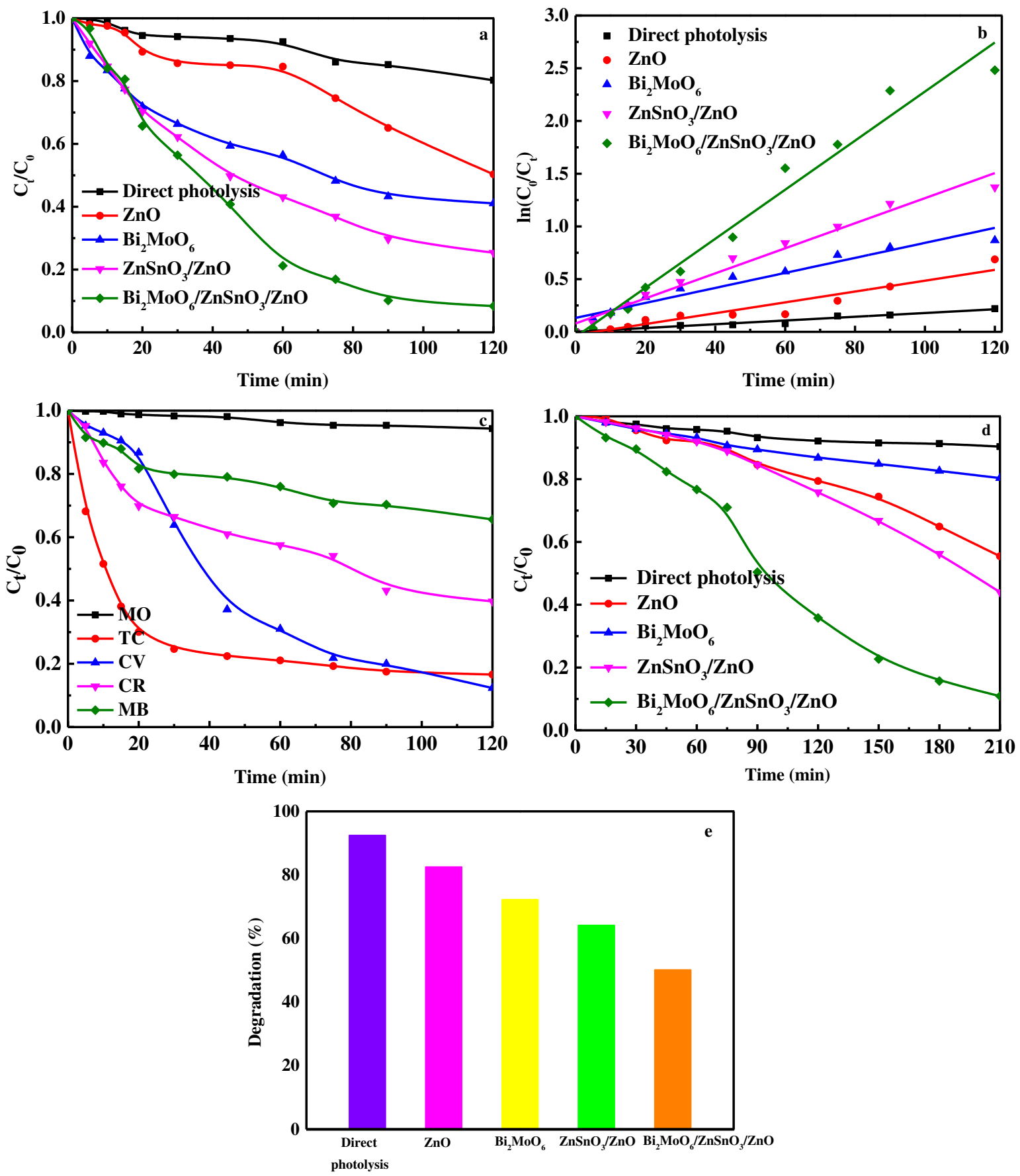

Fig 8 (a) Degradation of CV by different catalysts under ultraviolet light ( $\mathrm{t}=120 \mathrm{~min}$ ), (b) Corresponding pseudo first order kinetic fitting curves of different catalysts under UV light irradiation, (c) Experimental results of degradation of different organic pollutants by $\mathrm{Bi}_{2} \mathrm{MoO}_{6} / \mathrm{ZnSnO}_{3} / \mathrm{ZnO}$ under ultraviolet light, (d) Degradation of CV by different catalysts under visible light ( $\mathrm{t}=210 \mathrm{~min}$ ), (e) Degradation of CV by different catalysts under simulated sunlight $(\mathrm{t}=300 \mathrm{~min})$. 
In order to investigate the reaction kinetics of the photocatalytic degradation of crystal violet by $\mathrm{ZnO}, \mathrm{Bi}_{2} \mathrm{MoO}_{6}, \mathrm{ZnSnO}_{3} / \mathrm{ZnO}$ and $\mathrm{Bi}_{2} \mathrm{MoO}_{6} / \mathrm{ZnSnO}_{3} / \mathrm{ZnO}$, the Langmuir Hinshelwood equation (Eq 3) is fitted to the experimental data in Fig 9 (a):

$$
\ln \left(C_{0} / C_{t}\right)=K a p p t
$$

where $\mathrm{C}_{0}, \mathrm{C}_{\mathrm{t}}$ are the initial and residual concentrations of crystal violet in the reaction mixture $(\mathrm{mg} / \mathrm{L}), \mathrm{Kapp}$ is the pseudo-first-order rate constant for photocatalytic degradation $\left(\mathrm{min}^{-1}\right), \mathrm{t}$ is the time (min), and the linear fitted curve with irradiation time is shown in Fig 8 (b). Fig 8 (b) shows that $\ln \left(\mathrm{C}_{0} / \mathrm{C}_{\mathrm{t}}\right)$ has a linear relationship with the reaction time $\mathrm{t}$, indicating that the degradation of dye molecules follows the pseudo-first-order reaction kinetics. The photocatalytic activity of the $\mathrm{Bi}_{2} \mathrm{MoO}_{6} / \mathrm{ZnSnO}_{3} / \mathrm{ZnO}$ composite is determined by testing its activity in the degradation of crystal violet under visible light and simulated sunlight, as shown in Fig 8 (d) and (e). $\mathrm{Bi}_{2} \mathrm{MoO}_{6} / \mathrm{ZnSnO}_{3} / \mathrm{ZnO}$ exhibits the optimal photocatalytic degradation efficiency within visible and simulated daylight irradiation. Besides, $\mathrm{Bi}_{2} \mathrm{MoO}_{6} / \mathrm{ZnSnO}_{3} / \mathrm{ZnO}$ shows high photocatalytic activity under multimode photocatalytic conditions, resulting from the heterostructure present in the composites.

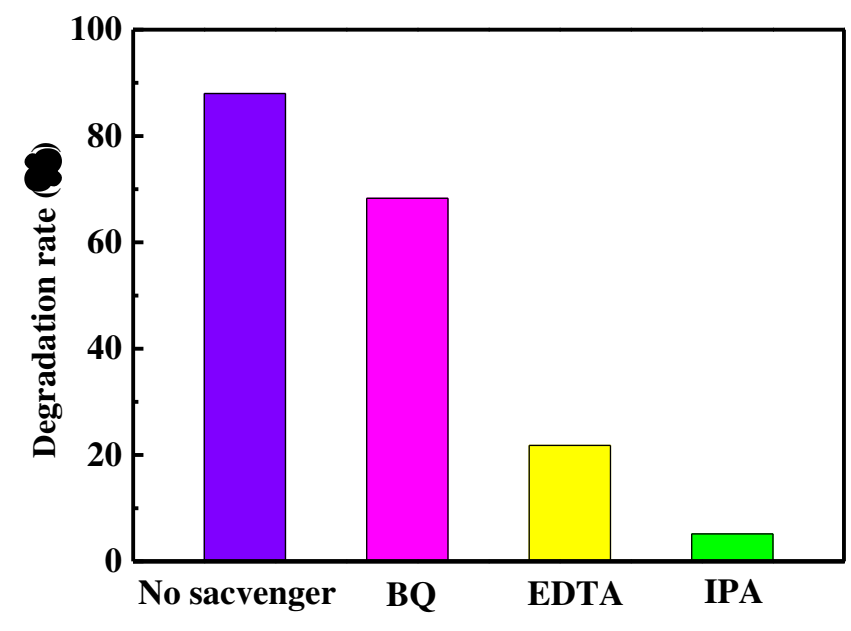

Fig 9 Capture experimental results of $\mathrm{Bi}_{2} \mathrm{MoO}_{6} / \mathrm{ZnSnO}_{3} / \mathrm{ZnO}$ under UV light.

In order to explore the reason that the composites have high photocatalytic activity, trapping experiments are performed, as shown in Fig 9. Under the same experimental conditions, superoxide radical $\left(\cdot \mathrm{O}_{2}^{-}\right)$, hydroxyl radical $\left(\cdot \mathrm{OH}^{-}\right)$and hole $\left(\mathrm{h}^{+}\right)$were trapped by adding p-benzoquinone (BQ), isopropanol (IPA) and disodium ethylenediaminetetraacetate (EDTA-2Na) under UV light irradiation, respectively, to get the capture experimental results. Fig. 9 shows that the degradation efficiency of CV appeared obviously different after different trapping agents were added under UV 
light irradiation. Among them, the degradation efficiency of crystal violet is suppressed after adding isopropanol (IPA) and disodium ethylenediaminetetraacetic acid (EDTA-2Na), indicating that the main active species in the photodegradation of $\mathrm{CV}$ by the $\mathrm{Bi}_{2} \mathrm{MoO}_{6} / \mathrm{ZnSnO}_{3} / \mathrm{ZnO}$ composite are hydroxyl radicals $\left(\cdot \mathrm{OH}^{-}\right)$and holes $\left(\mathrm{h}^{+}\right)$, while superoxide radicals $\left(\cdot \mathrm{O}_{2}^{-}\right)$plays a certain auxiliary role.

In order to investigate the stability of the composite, $\mathrm{Bi}_{2} \mathrm{MoO}_{6} / \mathrm{ZnSnO}_{3} / \mathrm{ZnO}$ is subjected to three cycling degradation tests under UV irradiation, as shown in Fig S5. After three-cycle tests, the $\mathrm{Bi}_{2} \mathrm{MoO}_{6} / \mathrm{ZnSnO}_{3} / \mathrm{ZnO}$ composite still has good photocatalytic degradation activity, indicating that the composite shows good stability.

\subsection{LC-MS analysis}



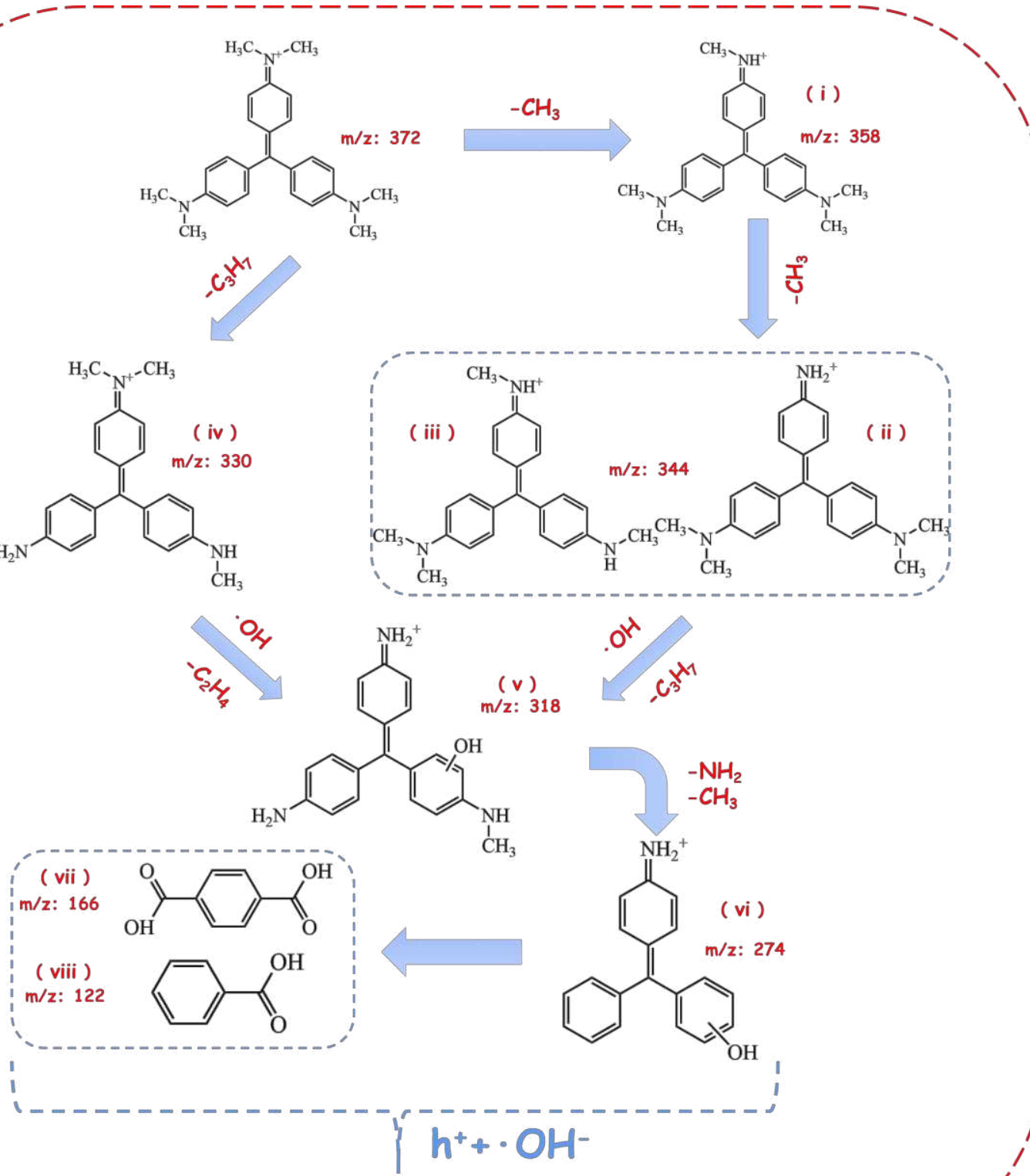

\section{Small molecule compounds (e.g. $\mathrm{CO}_{2}$ and $\mathrm{H}_{2} \mathrm{O}$ )}

Fig 10 Degradation pathway of $\mathrm{CV}$ on $\mathrm{Bi}_{2} \mathrm{MoO}_{6} / \mathrm{ZnSnO}_{3} / \mathrm{ZnO}$ composite under UV light irradiation.

In order to further explore the reaction mechanism of $\mathrm{CV}$ degradation by composite, $1 \mathrm{~mL}$ is sampled every 30 min interval by LC-MS to identify the intermediates of the reaction, and the possible degradation pathways of the corresponding intermediates and $\mathrm{CV}$ on $\mathrm{Bi}_{2} \mathrm{MoO}_{6} / \mathrm{ZnSnO} 3 / \mathrm{ZnO}$ are proposed [37, 38], as shown in Fig 10.

The comparison between the assay results and the standard database shows that the resulting degradation intermediates mainly consist of components (i), (ii), (iii), (iv), (v), (vi), (vii), (viii), etc. 
According to the above results and some previous reports, the possible photocatalytic degradation pathways of $\mathrm{Bi}_{2} \mathrm{MoO}_{6} / \mathrm{ZnSnO}_{3} / \mathrm{ZnO}$ can be further inferred, as shown in Fig 10 .

Hydroxyl radicals and metal cations attack the CV in the oxidized lattice formed on the surface of $\mathrm{Bi}_{2} \mathrm{MoO}_{6} / \mathrm{ZnSnO}_{3} / \mathrm{ZnO}$ composites, and the chemical names and molecular formulas of the generated components are shown in Table S2. Finally, hydroxyl radicals promote oxidative ring opening reactions to generate some simpler small molecule compounds, which are finally converted to $\mathrm{H}_{2} \mathrm{O}, \mathrm{CO}_{2}$, and inorganic ions.

\subsection{Possible photocatalytic reaction mechanism}

To explore the migration path of photogenerated carriers in the composite photocatalysts $\mathrm{Bi}_{2} \mathrm{MoO}_{6} / \mathrm{ZnSnO}_{3} / \mathrm{ZnO}$, the positions of the energy bands are calculated using Eq (4) and (5), as shown in Table 2.

$$
\begin{gathered}
E_{C B}=\chi-E_{C}-0.5 \cdot E_{g} \\
E_{V B}=E_{C B}+E_{g}
\end{gathered}
$$

In these formulas, $X$ is the absolute value of the absolute electronegativity of the semiconductor photocatalyst. $E_{c}$ is the standard hydrogen electrode potential $(4.5 \mathrm{eV}) . E_{V B}$ and $E_{C B}$ are the energy band positions of valence and conduction bands of composites, respectively, and $E g$ is the band gap value of the semiconductor.

Table 2 Absolute electronegativity ( $\chi$ ), band gap energy (Eg), conduction band (CB), valence band (VB) of $\mathrm{ZnO}, \mathrm{ZnSnO}_{3}$, and $\mathrm{Bi}_{2} \mathrm{MoO}_{6}$.

\begin{tabular}{ccccc}
\hline Semiconductor & $\chi / \mathrm{eV}$ & $\mathrm{Eg} / \mathrm{eV}$ & $\mathrm{E}_{\mathrm{CB}} / \mathrm{eV}$ & $\mathrm{E}_{\mathrm{VB}} / \mathrm{eV}$ \\
\hline $\mathrm{ZnO}$ & 5.79 & 3.24 & -0.33 & 2.91 \\
$\mathrm{ZnSnO}_{3}$ & 6.06 & 3.16 & -0.002 & 3.14 \\
$\mathrm{Bi}_{2} \mathrm{MoO}_{6}$ & 6.31 & 2.68 & 0.47 & 3.15 \\
\hline
\end{tabular}

The possible photocatalytic mechanism of the $\mathrm{Bi}_{2} \mathrm{MoO}_{6} / \mathrm{ZnSnO}_{3} / \mathrm{ZnO}$ composites is speculated from the above calculation results and the trapping experiment results, as shown in Fig 11. 


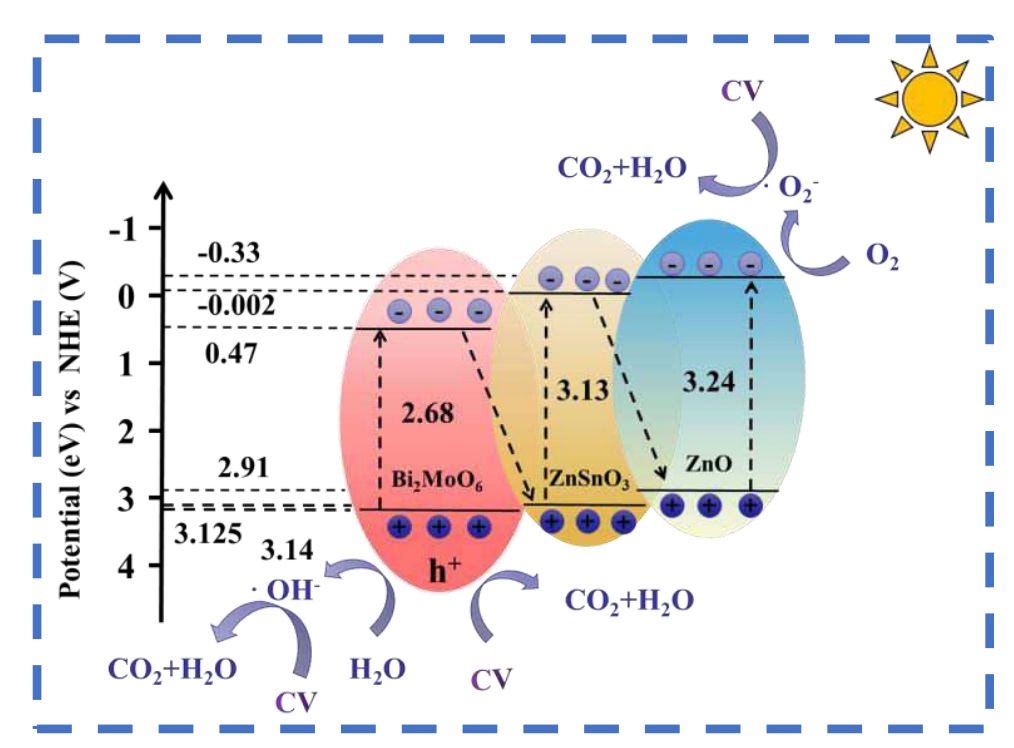

Fig 11 Possible photocatalytic reaction mechanism of $\mathrm{Bi}_{2} \mathrm{MoO}_{6} / \mathrm{ZnSnO} / / \mathrm{ZnO}$ under simulated sunlight irradiation.

During the synthesis of the composites, heterojunctions were formed due to the matching of energy bands. Under simulated sunlight irradiation, the components in the $\mathrm{Bi}_{2} \mathrm{MoO}_{6} / \mathrm{ZnSnO}_{3} / \mathrm{ZnO}$ composites absorb the ultraviolet light component in simulated daylight. Therefore, the photogenerated electrons are excited from the valence band (VB) to its conduction band of the composites (CB), and the same number of holes are retained in the VB. In this process, due to the heterojunction, a double Z-bridge structure appears in the electron transport pathway in the $\mathrm{Bi}_{2} \mathrm{MoO}_{6} / \mathrm{ZnSnO}_{3} / \mathrm{ZnO}$ composite. The electrons on the conduction band of $\mathrm{ZnSnO}$ and $\mathrm{Bi}_{2} \mathrm{MoO}_{6}$ are complexed with the holes on the valence band of $\mathrm{ZnO}$ and $\mathrm{ZnSnO}_{3}$, and rapid electron transfer is achieved. Only electrons at the conduction band of $\mathrm{ZnO}$ react with dissolved oxygen to generate superoxide radical $\left(\cdot \mathrm{O}_{2}^{-}\right)$, and holes $\left(\mathrm{h}^{+}\right)$at the valence band of $\mathrm{Bi}_{2} \mathrm{MoO}_{6}$ react with water molecules to generate hydroxyl radical $\left(\cdot \mathrm{OH}^{-}\right) \cdot\left(\cdot \mathrm{O}_{2}^{-}\right),\left(\cdot \mathrm{OH}^{-}\right)$, and $\mathrm{h}^{+}$react with organic pollutants to generate carbon dioxide $\left(\mathrm{CO}_{2}\right)$, water $\left(\mathrm{H}_{2} \mathrm{O}\right)$, and inorganic ions, respectively, and then successfully degrade pollutants.

\section{Conclusion}

The composite $\mathrm{Bi}_{2} \mathrm{MoO} / \mathrm{ZnSnO}_{3} / \mathrm{ZnO}$ with interfacial contact was synthesized by the hydrothermal method. Compared with monomeric $\mathrm{ZnO}$ and $\mathrm{ZnSnO}_{3} / \mathrm{ZnO}$, the photocatalytic activity of the $\mathrm{Bi}_{2} \mathrm{MoO}_{6} / \mathrm{ZnSnO}_{3} / \mathrm{ZnO}$ composite is enhanced under multimode light. The photoelectrochemical test shows that the photoelectric current response of the $\mathrm{Bi}_{2} \mathrm{MoO}_{6} / \mathrm{ZnSnO}_{3} / \mathrm{ZnO}$ composite is higher than that of its components, while the electrochemical 
impedance is low, demonstrating that the photogenerated electrons and holes in the composite are effectively separated and transferred. The construction of hierarchical double $\mathrm{Z}$ scheme heterojunction between $\mathrm{ZnO}, \mathrm{ZnSnO}_{3}$, and $\mathrm{Bi}_{2} \mathrm{MoO}_{6}$ is the main reason for the improved photocatalytic activity and charge separation efficiency of the composites. Besides, the $\mathrm{Bi}_{2} \mathrm{MoO}_{6} / \mathrm{ZnSnO}_{3} / \mathrm{ZnO}$ composite still maintains good stability after 3 cycles. The above research shows that $\mathrm{Bi}_{2} \mathrm{MoO}_{6} / \mathrm{ZnSnO}_{3} / \mathrm{ZnO}$ composite is a promising photocatalytic material for wastewater treatment.

\section{Acknowledgments}

This study was supported by the National Natural Science Foundation of China (21776144, 21376126), the Heilongjiang Provincial Natural Science Foundation of China (LH2021B031), the Innovation Project of Qiqihar University Graduate Education (YJSCX2020037), and the College Students' Innovative Entrepreneurial Training Program Funded Projects of Qiqihar University (202110232154).

\section{Conflicts of interest}

There are no conflicts to declare.

\section{References}

[1] P. Zhu, J. Xu, M. Duan, R. Wang, L. Xie, M. Hu, P. Wang, Opt. Mater 107, 110076 (2020)

[2] M. Pirhashemi, A. Habibi-Yangjeh, Mater. Chem. Phys. 214, 107 (2018)

[3] A.I.J. Joseph, S. Thiripuranthagan, RSC Adv. 5, 9792 (2015).

[4] D. Reddy, M. Sahik, S. Challapalli, Theor Anal. Chem. 53, 499 (2014).

[5] J. Singh, S. Kumar, Rishikesh, A.K. Manna, R.K. Soni, Opt. Mater 107, 110138 (2020).

[6] T. Kanagaraj, S. Thiripuranthagan, S.M.K. Paskalis, H. Abe, Appl. Surf. Sci.426, 1030 (2017).

[7] M.K. Singha, A. Patra, Opt. Mater 107, 110000 (2020).

[8] M. Kasinathan, S. Thiripuranthagan, A. Sivakumar, S. Ranganathan, T. Vembuli, S. Kumaravel, E. Erusappan, , Mater. Res. Bull. 125, 110782 (2020).

[9] B. Appavu, S. Thiripuranthagan, S. Ranganathan, E. Erusappan, K. Kannan, Ecotoxicol. Environ. Saf. 151, 118 (2018).

[10] H.J. Jung, R. Koutavarapu, S. Lee, J.H. Kim, H.C. Choi, M.Y. Choi, J. Alloys Compd. 735, 2058 (2018). 
[11] X. An, J.C. Yu, F. Wang, C. Li, Y. Li, Appl. Catal. B 129, 80 (2013).

[12] C. N. Ri, S. G. Kim, K. S. Ju, H.-S. Ryo, C. H. Mun, U.H. Kim, RSC Adv. 8, 5433 (2018).

[13] F. Guo, W. Shi, W. Guan, H. Huang, Y. Liu, Sep. Purif. Technol. 173, 295 (2017).

[14] J. Yu, S. Zhuang, X. Xu, W. Zhu, B. Feng, J. Hu, J. Mater. Chem. A 3, 1199 (2015).

[15] P. Y. Kuang, J. R. Ran, Z. Q. Liu, H. J. Wang, N. Li, Y. Z. Su, Y. G. Jin, S. Z. Qiao, Chem. Eur. J. 21, 15360 (2015).

[16] Y. Wang, R. Shi, J. Lin, Y. Zhu, Energy Environ. Sci. 4, 2922 (2011).

[17] N. Li, Y. Tian, J. Zhao, J. Zhang, W. Zuo, L. Kong, H. Cui, Chem. Eng. J. 352, 412 (2018).

[18] C. Wang, H. Lin, Z. Liu, J. Wu, Z. Xu, C. Zhang, Part Part Syst Charact 33, 221 (2016).

[19] Y. Ma, Q. Xie, X. Liu, Y. Zhao, D. Zeng, L. Wang, Y. Zheng, D. L. Peng, Electrochim. Acta 182, 327 (2015).

[20] M. K. Lo, S.-Y. Lee, K. S. Chang, J. Phys. Chem. C 119, 5218 (2015).

[21] Z. Wang, J. Miao, H. Zhang, D. Wang, J. Sun, J. Hazard. Mater. 391, 122226 (2020).

[22] S. Yu, X. Jia, J. Yang, S. Wang, Y. Li, H. Song, Mater. Lett. 291, 129531 (2021).

[23] D. Lian, B. Shi, R. Dai, X. Jia, X. Wu, J Nanopart Res 19, 401 (2017).

[24] S. Adhikari, S. Selvaraj, D. H. Kim, Appl. Catal. B 244, 11 (2019).

[25] J. Ding, Z. Yang, C. He, X. Tong, Y. Li, X. Niu, H. Zhang, J. Colloid Interface Sci. 497, 126 (2017).

[26] Y. Yan, J. Liu, H. Zhang, D. Song, J. Li, P. Yang, M. Zhang, J. Wang, J. Alloys Compd. 780, 193 (2019).

[27] V. H. Nguyen, M. Mousavi, J.B. Ghasemi, Q.V. Le, S.A. Delbari, M. Shahedi Asl, M. Mohammadi, M. Shokouhimehr, A. Sabahi Namini, J TAIWAN INST CHEM E 118, 140 (2021).

[28] G.U. Siddiqui, M.M. Rehman, K.H. Choi, J. Mater. Chem. C 5, 5528 (2017).

[29] M. Kasinathan, S. Thiripuranthagan, A. Sivakumar, Opt. Mater 109, 110218 (2020).

[30] Y. Liu, Z.-H. Yang, P.-P. Song, R. Xu, H. Wang, Appl. Surf. Sci. 430, 561 (2018).

[31] L. Du, H. Zhang, M. Zhu, M. Zhang, Inorg. Chem. Front. 6, 2311 (2019).

[32] M. Zhang, C. Shao, J. Mu, Z. Zhang, Z. Guo, P. Zhang, Y. Liu, CrystEngComm 14, 605 (2012).

[33] W. Zhou, Z. Yin, Y. Du, X. Huang, Z. Zeng, Z. Fan, H. Liu, J. Wang, H. Zhang, Small 9, 140 
(2013).

[34] C.H. Nguyen, M.L. Tran, T.T.V. Tran, R.-S. Juang, Sep. Purif. Technol. 232, 115962 (2020).

[35] G. Zhang, D. Chen, N. Li, Q. Xu, H. Li, J. He, J. Lu, Appl. Catal. B 250, 313 (2019).

[36] H. Li, W. Hong, Y. Cui, Q. Jia, S. Fan, J Mol Catal A Chem 378, 164 (2013).

[37] H. He, S. Yang, K. Yu, Y. Ju, C. Sun, L. Wang, J. Hazard. Mater.173, 393 (2010).

[38] G. Favaro, D. Confortin, P. Pastore, M. Brustolon, J Mass Spectrom. 47, 1660 (2012).

\section{Statements and Declarations}

Funding: This work was supported by [the National Natural Science Foundation of China, the Heilongjiang Provincial Natural Science Foundation of China, the Innovation Project of Qiqihar University Graduate Education and the College Students' Innovative Entrepreneurial Training Program Funded Projects of Qiqihar University] (Grant numbers [21776144, 21376126] and [LH2021B031] and [YJSCX2020037] and [202110232154]).

Competing Interests: The authors have no relevant financial or non-financial interests to disclose.

Author Contributions: The first draft of the manuscript was written by [Yuanyingxue Gao] and revised by [ $\mathrm{Li} \mathrm{Li}]$ and all authors commented on previous versions of the manuscript. Material preparation, data collection and analysis were performed by [Yuanyingxue Gao], [Li Li], [Wenlin $\mathrm{Zu}$ ] and [Yingru Sun]. Technical support and supervision of instrument operation were provided by [Yianzhen Cao] and [Wenzhi Zhang]. Manuscript preservation and visualization were provided by [Guan Jiahui] and [Yu Haixia].

Data Availability: The datasets generated during and/or analyzed during the current study are available from the corresponding author on reasonable request. 


\section{Supplementary Files}

This is a list of supplementary files associated with this preprint. Click to download.

- SupplementaryMaterial.docx 